\title{
Lead Slowing Down Spectrometer Status Report
}

$\begin{array}{ll}\text { GA Warren } & \text { A Gavron }^{3} \\ \text { K Anderson } & \text { RC Haight } \\ \text { E Bonebrake } & \text { G Imel }^{1} \\ \text { AM Casella } & \text { J Kulisek }^{1} \\ \text { Y Danon }^{2} & \text { JM O'Donnell }^{3} \\ \text { M Devlin }^{3} & \text { A Weltz }^{2}\end{array}$

June 2012

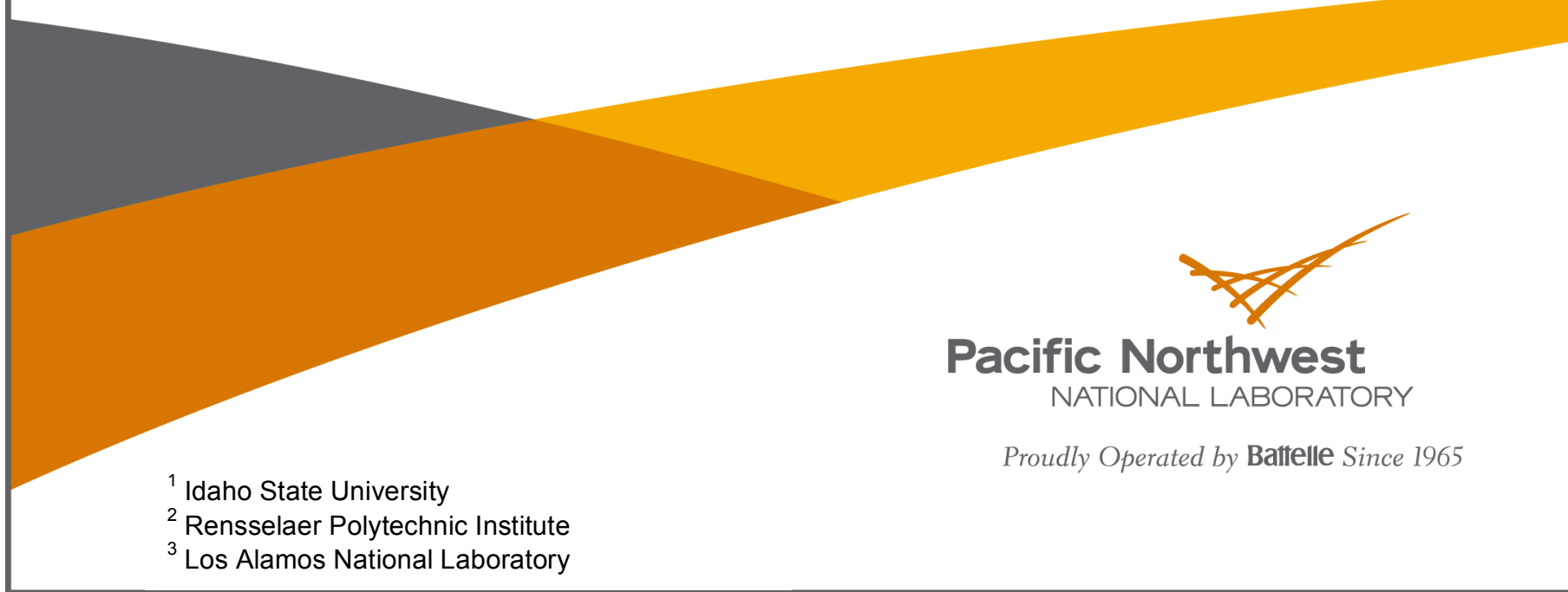




\title{
DISCLAIMER
}

This report was prepared as an account of work sponsored by an agency of the United States Government. Neither the United States Government nor any agency thereof, nor Battelle Memorial Institute, nor any of their employees, makes any warranty, express or implied, or assumes any legal liability or responsibility for the accuracy, completeness, or usefulness of any information, apparatus, product, or process disclosed, or represents that its use would not infringe privately owned rights. Reference herein to any specific commercial product, process, or service by trade name, trademark, manufacturer, or otherwise does not necessarily constitute or imply its endorsement, recommendation, or favoring by the United States Government or any agency thereof, or Battelle Memorial Institute. The views and opinions of authors expressed herein do not necessarily state or reflect those of the United States Government or any agency thereof.

\author{
PACIFIC NORTHWEST NATIONAL LABORATORY \\ operated by \\ BATTELLE \\ for the \\ UNITED STATES DEPARTMENT OF ENERGY \\ under Contract DE-AC05-76RL01830
}

Printed in the United States of America
Available to DOE and DOE contractors from the Office of Scientific and Technical Information,
P.O. Box 62, Oak Ridge, TN 37831-0062;
ph: (865) 576-8401
fax: $(865)$ 576-5728
email: reports@adonis.osti.gov

\begin{abstract}
Available to the public from the National Technical Information Service, U.S. Department of Commerce, 5285 Port Royal Rd., Springfield, VA 22161 ph: (800) 553-6847 fax: $(703) 605-6900$ email: orders@ntis.fedworld.gov online ordering: http://www.ntis.gov/ordering.htm
\end{abstract}

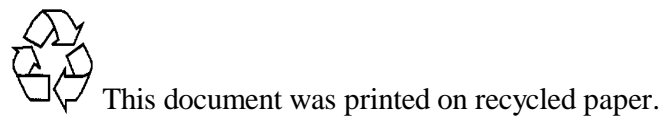




\section{Lead Slowing Down Spectrometer Status Report}

$\begin{array}{ll}\text { GA Warren } & \text { VA Gavron } \\ \text { KK Anderson } & \text { RC Haight } \\ \text { E Bonebrake }^{3} & \text { GR Imel }^{1} \\ \text { AM Casella } & \text { JA Kulisek }^{\text {Y Danon }} \\ \text { Y Danon }^{2} & \text { JM O'Donnell }^{3} \\ \text { M Devlin }^{3} & \text { A Weltz }^{2}\end{array}$

June 2012

Prepared for

the U.S. Department of Energy under Contract DE-AC05-76RL01830

Pacific Northwest National Laboratory Richland, Washington 99352

\footnotetext{
${ }^{1}$ Idaho State University

${ }^{2}$ Rensselaer Polytechnic Institute

${ }^{3}$ Los Alamos National Laboratory
} 



\section{Executive Summary}

This report documents the progress in the first half of FY2012 toward completion of the MPACT-funded Lead Slowing-Down Spectrometer project. Significant progress has been made on the algorithm development. We have an improved understanding of the experimental responses in LSDS for fuelrelated material. The calibration of the ultra-depleted uranium foils was completed, but the results are inconsistent from measurement to measurement. Future work includes developing a conceptual model of an LSDS system to assay plutonium in used fuel, improving agreement between simulations and measurement, design of a thorium fission chamber, and evaluation of additional detector techniques. 



\section{Acronyms and Abbreviations}

ISU

LANL

LSDS

MCNP

PNNL

RMSE

RPI

SFL1

$\mathrm{uDU}$
Idaho State University

Los Alamos National Laboratory

Lead Slowing-Down Spectrometer

Monte Carlo N-Particle Transport Code

Pacific Northwest National Laboratory

Root-mean-square error

Rensselaer Polytechnic Institute

Spent Fuel Library 1

Ultra-depleted uranium 



\section{Contents}

Executive Summary ……..................................................................................................................................iii

Acronyms and Abbreviations ................................................................................................................. v

$1.0 \quad$ Introduction ................................................................................................................. 1

2.0 Algorithm Development......................................................................................... 1

3.0 LSDS Measurements....................................................................................................... 2

$3.1 \quad$ LANL . .

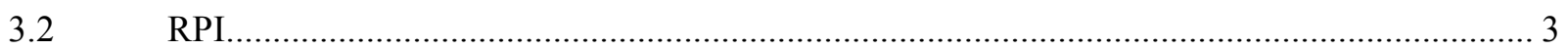

4.0 Fission Chamber Development …………….................................................................... 4

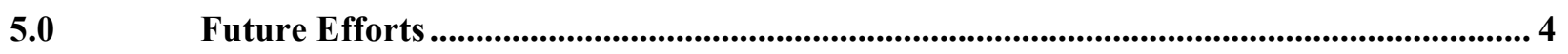

6.0 Publications, Presentations, and Notables .............................................................................. 5

7.0 References ............................................................................................................................. 6 



\subsection{Introduction}

The MPACT-funded Lead Slowing-Down Spectrometer (LSDS) project is studying whether LSDS techniques can be applied to the direct assay of plutonium in used nuclear fuel. The project is a collaborative effort between Pacific Northwest National Laboratory (PNNL), Los Alamos National Laboratory (LANL), Rensselaer Polytechnic Institute (RPI) and Idaho State University (ISU). The effort includes algorithm development, experimental validation, and detector development. This is a status report on the progress made by the collaboration in the first half of FY2012. For the sake of brevity, the report will focus on results and conclusions. The report will conclude with a discussion of future work.

\subsection{Algorithm Development}

In FY2011, PNNL developed an algorithm that relied on calibration against a set of known fuel assemblies, and then used those calibrations to extract the masses from the unknown fuel assemblies. The effort in FY2012 has been focused on determining whether the algorithm can be practically applied. We test the algorithms against the NGSI 64 (SFL1) library of used fuel (Tobin et al., 2009), to determine the accuracy of the algorithm against a wide range of fuel types. We expressed the uncertainty for the extracted masses over the entire library using the root-mean-square error (RMSE), which reflects both systematic accuracy across the fuel library and statistical precision of each measurement. For these calculations, we assumed $10^{16}$ source neutrons. All NGSI 64-related accuracy and precision results quoted in this section are the relative RMSE of the differences between the actual and extracted masses of ${ }^{239} \mathrm{Pu}+{ }^{241} \mathrm{Pu}$. A summary of our findings for the calibration model that uses Singular Value Decomposition (Golub and Reinsch, 1970) to approximate the self-attenuation follows:

1. Decreasing the calibration set from the entire 64 fuel assemblies of the NGSI 64 down to a calibration set of 6 increased the RMSE of ${ }^{239} \mathrm{Pu}+{ }^{241} \mathrm{Pu}$ mass from $1 \%$ to $1.8 \%$ for the NGSI 64 .

2. Allowing for the calibration masses to have a $2 \%$ uncertainty increased the RMSE of ${ }^{239} \mathrm{Pu}+{ }^{241} \mathrm{Pu}$ mass from $1.8 \%$ to $2.7 \%$ for the NGSI 64 .

3. When the algorithm is calibrated with 6 of the NGSI 64 fuel assemblies, the algorithm can determine the ${ }^{239} \mathrm{Pu}+{ }^{241} \mathrm{Pu}$ mass with an RMSE of $1.5 \%$ for the 27 diversion cases.

It is important to note that these results have been developed within a specific model. Once considerations such as geometric variations, detector variability, and source variability are accounted for, the uncertainty of the approach may increase.

We also studied the spatial sensitivity of the fuel assembly to the interrogation process. It was found that the interrogating neutron flux (below $10 \mathrm{keV}$ ) in the center of the assembly is roughly $90 \%$ of that at the outer edge of the assembly. However, the signal observed by the assay detectors outside of the assembly originating from the center of the assembly is $55 \%$ of that originating from the outer edge of the assembly. Due to how the tally was conducted in MCNP, it is likely that the contribution from the center of the assembly is underestimated.

We have been investigating alternative algorithms that do not require the isotopic fission chamber response. These algorithms would therefore not require "exotic" fission chambers such as ${ }^{239} \mathrm{Pu}$ and 
${ }^{241} \mathrm{Pu}$. The first attempt at a linear model relating the assay signal (signal sensitive to only fast neutrons) to the isotopic masses demonstrated accuracies comparable to the prior analytical model. However, a model that extends that effort to second-order terms, i.e., quadratic in the masses, including possible correlations, is under development at this time.

We are investigating the impact of statistical noise in the analysis. The analysis engine for extracting the masses from the assay and isotopic fission chamber signals introduces statistical noise into the spectrum. The level of the noise is related to the detector efficiencies and the target number of source neutrons. This noise is placed onto spectra generated by MCNP; these MCNP spectra also have noise. It has been determined that the MCNP noise is as large as or larger than the statistical noise introduced by the analysis engine for times less than $1 \mu \mathrm{s}(<0.25 \mathrm{keV})$. Thus, it is possible that the accuracy of the algorithm may improve if the MCNP statistical noise can be further reduced. We are currently working on decreasing the MCNP statistical noise to understand the possible impact on the algorithm's accuracy.

Finally, we are investigating the validity of determining the accuracy of the algorithms against the entire NGSI 64. The NGSI 64 was intended to reflect the range of fuels one is likely to encounter for international safeguards. This MPACT-funded work is focused on domestic safeguards, so the relevant set is the current US inventory of used fuel. This set has certain correlations between the various parameters. For instance, over time, burnup for fuel assemblies has increased. To enable those higher burnups, the initial uranium enrichment must also increase. This also implies a correlation between burnup and cooling time; e.g., higher burnups will correspond to shorter cooling times. We are examining the information about the US inventory of used fuel to determine the relevant range of initial enrichment, burnup and cooling time to reflect domestic safeguard concerns.

\subsection{LSDS Measurements}

\subsection{LANL}

The LANL effort in the last year concentrated on several items: first and foremost, a major fraction of the effort was devoted to comparing experimental data with simulation results. In these studies, we used a threshold fission detector (ion chamber) incorporating $37 \mathrm{mg}$ of ${ }^{232} \mathrm{Th}$ to detect fission neutrons emitted by sample foils. There were two samples: 23 grams of ${ }^{235} \mathrm{U}$, and 25 grams of plutonium, of which about $94 \%$ was ${ }^{239} \mathrm{Pu}$. The samples were placed in the same channel of the lead stack as the threshold detector. The time dependence of the fast neutrons detected in the threshold detector was measured relative to a "start" signal derived from the arrival of the proton pulse from the proton storage ring.

There were significant differences between the experimental results and the simulation calculations (using the MCNPX neutron transport code with the ENDF-B/VII library). These are summarized in Figure 1. 


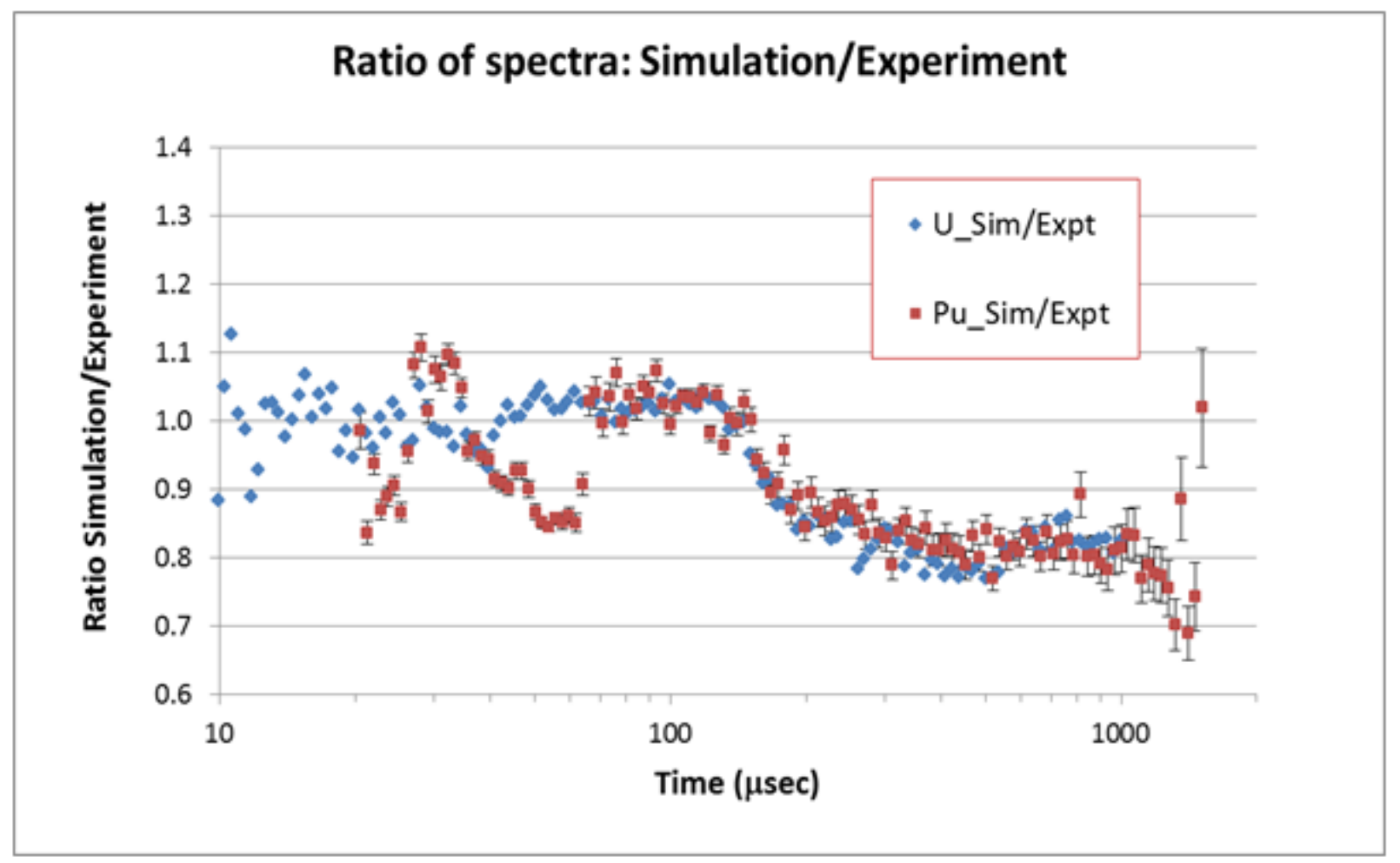

Figure 1: Ratio of simulated spectra to experimental spectra as a function of time. Blue diamonds represent the ${ }^{235} \mathrm{U}$ sample, and red squares the ${ }^{239} \mathrm{Pu}$ sample. Uncertainties are statistical only.

We note that both samples show the same discrepancy above $120 \mu \mathrm{s}$, and in addition, there is a significant discrepancy with the ${ }^{239} \mathrm{Pu}$ data at shorter times. Possibly, the discrepancy is a result at least in part of room reflection that is incompletely included in the simulation.

Additional effort was invested in developing a different type of fast neutron detector (potentially increasing the detection efficiency by three to four orders of magnitude) using the recoil of ${ }^{4} \mathrm{He}$ nuclei (in a helium-filled proportional counter) when impacted by fast neutrons. We found that the recovery time after the initial pulse was too slow to be able to utilize this detector. We are now considering the use of its scintillation properties instead.

Another effort involved the development of a perturbation method to analyze the isotopic content of spent fuel. This effort is currently underway and needs further development before we can draw any conclusions.

\subsection{RPI}

RPI has studied the effect of room return, neutrons that exit the lead stack and then later reenter. The room-return contributes to flux monitor responses, and this is dependent on the detector position in the lead. Detectors closer to the exterior (especially those nearer to the external concrete structure) of the LSDS see more of a contribution from room-return. The discrepancies were reduced by covering the flux monitor ports with lithium carbonate. This material was a stronger absorber of room- return neutrons, 
which have a harder spectrum than initially thought. Additionally, the agreement between the MCNP simulation and experimental data for the assay detector can be improved by filling the void more completely with lead. Reducing this void will lessen the impact of returning neutrons and improve the time-energy correlation characteristic of this LSDS.

As expected, the discrepancy of non-hydrogenous impurities from the two chemical analyses, one conducted in 1971 and one in 2012, has a minimal effect on the MCNP detector tallies. However, the 2012 analysis provided improved agreement for the ${ }^{235} \mathrm{U}$ fission chamber in the region of 700-2000 $\mu \mathrm{s}$, which could be due to the $0.01 \mathrm{ppm}$ of samarium and gadolinium, which have strong neutron-absorbing isotopes. Subsequent analysis will include the examination of the effect these impurities have on the ${ }^{238} \mathrm{U}$ and ${ }^{232} \mathrm{Th}$ fission chamber assay detectors.

\subsection{Fission Chamber Development}

Idaho State University completed the calibration of a set of ultra-depleted uranium (uDU) foils. To obtain accurate measurements of the neutron flux with a fission chamber, the uranium foils being used must be calibrated. A back-to-back fission chamber can be used for cross calibration between a calibrated and an uncalibrated uranium foil. Back-to-back cross calibration measurements were made using the AGN-201 reactor at ISU, the Idaho Accelerator Center's $25 \mathrm{MeV}$ electron accelerator on a tungsten converter, and an americium-beryllium neutron source in the open air that was surrounded with paraffin wax to create a semi-thermal neutron field. There was considerable variation in the results for these different neutron sources. The most accurate results came from the americium-beryllium source in open air, resulting in masses of $171.8,155.7$ and $143.3 \mu \mathrm{g}$ for the three separate ${ }^{238} \mathrm{U}$ foils. Some, if not all, of the variability of the results may be due to loss of material on foils during handling, inconsistent placement of detectors, and variations in thickness of material on foils.

ISU has started to work on designing a thorium-based fission chamber for the next stage of the project.

\subsection{Future Efforts}

For the remaining months of the fiscal year, PNNL is focusing its efforts on conceptual design, algorithms that require only the fast neutron signal, and testing its algorithms against data provided by RPI. The conceptual design will justify and document the lead size, the neutron source requirements, and detector requirements. LANL is continuing to explore the perturbation model for analysis, as well as the possibility of using ${ }^{4} \mathrm{He}$ proportional counters as a fast neutron detector. RPI is anticipating approval from the Nuclear Regulatory Commission around July 2012, which would enable the conduction of measurements on a fresh fuel assembly. RPI will continue a modeling effort to plan for these measurements. ISU will evaluate possible thorium fission chamber designs. 


\subsection{Publications, Presentations, and Notables}

- Janelle Droessler (UNLV) was presented with the First Place Award in the Radiochemistry Division of the 2012 Student Conference of the American Nuclear Society. Her presentation featured some of her work with uDU that was funded by the MPACT and NEUP this year.

- Gavron, A, RC Haight, M Devlin and JM O'Donnell. 2012. MPACT FY2012 LANL Report - Analysis of LANSCE Experimental Results. Report, LA-UR-12-01274, Los Alamos National Laboratory, Los Alamos, NM.

- A. Gavron presented a talk "Spent Fuel Assay with Lead Slowing Down Spectrometer: Experiments and Analysis" (LA-UR-12-01042) at the MPACT Working Group meeting in Aiken, GA on March 13, 2012.

- Dr. Warren (PNNL) presented a talk "Lead Slowing-Down Spectrometry for Direct Measurement of $\mathrm{Pu}$ in Used Fuel" (PNNL-SA-86340) at the MPACT Working group meeting in Aiken, GA on March 13, 2012.

- Dr. Kulisek (PNNL) presented a contributed talk "Assaying Used Nuclear Fuel Assemblies Using Lead Slowing-Down Spectroscopy and Singular Value Decomposition" (PNNL-SA-87862) at SORMA West 2012, Oakland, CA on May 17, 2012.

- Prof. Danon (RPI) presented an invited talk "Lead Slowing-Down Spectrometer for Assay of Used Nuclear Fuel", at the Workshop on characterization of spent and melted fuel by non-destructive analysis (NDA) of the JRC-IRMM in Geel, Belgium on May 22, 2012. 
PNNL-21457

\subsection{References}

Tobin, SJ, MA Schear, A Rajasingum, NP Sandoval, BA Ludewigt, BJ Quiter, ML Fensin, M T Swinhoe, SJ Thompson, SY Lee, HO Menlove, and LE Smith. 2009. "Determination of Plutonium Content in Spent Fuel with Nondestructive Assay," in Proceedings of the $50^{\text {th }}$ Annual Meeting of the Institute of Nuclear Materials Management, July 12-15, 2009, Tucson, AZ. Institute of Nuclear Materials Management, Northbrook, Illinois.

Golub, G. H. and C. Reinsch (1970). "Singular Value Decomposition and Least Squares Solutions." Numerische Mathematik 14(5): 403-420. 



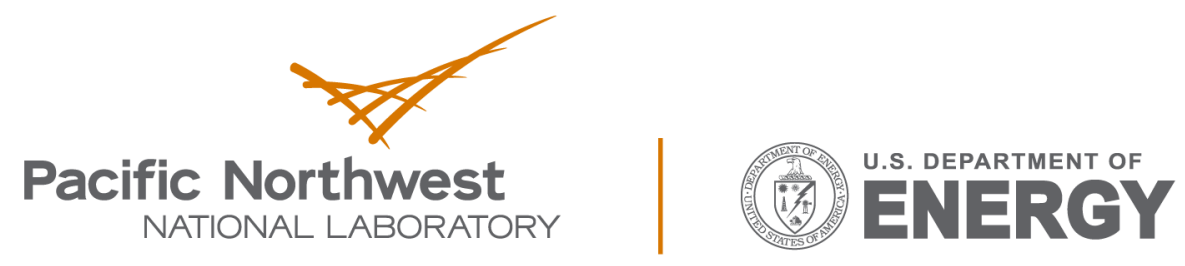

Proudly Operated by Battelle Since 1965

902 Battelle Boulevard

P.O. Box 999

Richland, WA 99352

1-888-375-PNNL (7665)

www.pnnl.gov 